\title{
REVISED Case Report: Atypical Cornelia de Lange Syndrome
}

\section{[version 2; peer review: 1 approved, 2 approved with}

\section{reservations]}

\author{
Vito Leanza, Gabriella Rubbino, Gianluca Leanza
}

Surgery Department, Obstetrics and Gynecologic Unit "Ospedale Santo Bambino”, Catania University, Catania, Italy

\author{
V2 First published: 31 Jan 2014, 3:33 \\ https://doi.org/10.12688/f1000research.3-33.v1 \\ Latest published: 27 May 2015, 3:33 \\ https://doi.org/10.12688/f1000research.3-33.v2
}

\section{Abstract}

Cornelia de Lange Syndrome (CdLS) (also called Bushy Syndrome or Amsterdam dwarfism), is a genetic disorder that can lead to several alterations. This disease affects both physical and neuropsychiatric development. The various abnormalities include facial dysmorphia (arched eyebrows, synophrys, depressed nasal bridge, long philtrum, down-turned angles of the mouth), upper-extremity malformations, hirsutism, cardiac defects, and gastrointestinal alterations. The prevalence of this syndrome is approximately one per 15,000. Ultrasound is not the perfect means to diagnose CdLS, however, many abnormalities can be detected prenatally by scrupulous image observation.

We report an atypical CdLS case characterized by increased nuchal translucency in the first trimester, normal karyotype, saddle nose, micrognathia with receding jaw, low set ears, facies senilis, arthrogryposis of the hands, absence of the Aranzio ductus venous, dilatation of gallbladder and bowel, a unique umbilical artery, increased volume of amniotic fluid, and intrauterine growth retardation ending with the interruption of pregnancy.

Keywords

facial dysmorphia, ultrasound

\section{Open Peer Review}

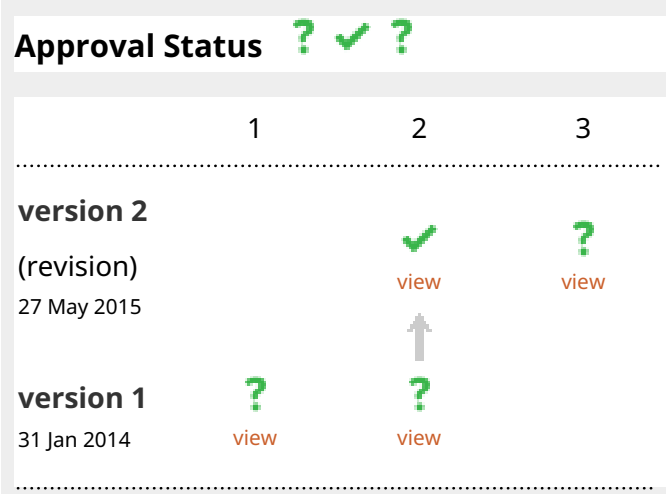

1. Jinglan Liu, Drexel University, Philadelphia, PA, USA

2. Laird Jackson, Drexel University, Philadelphia, PA, USA

3. Orkun Çetin, Istanbul Suleymaniye Birth and Gynecology Training and Research Hospital, Istanbul, Turkey

Any reports and responses or comments on the article can be found at the end of the article. 
Corresponding author: Vito Leanza (vito.leanza@gmail.com)

Competing interests: No competing interests were disclosed.

Grant information: The author(s) declared that no grants were involved in supporting this work.

Copyright: (c) 2015 Leanza V et al. This is an open access article distributed under the terms of the Creative Commons Attribution License , which permits unrestricted use, distribution, and reproduction in any medium, provided the original work is properly cited.

How to cite this article: Leanza V, Rubbino G and Leanza G. Case Report: Atypical Cornelia de Lange Syndrome [version 2; peer review: 1 approved, 2 approved with reservations] F1000Research 2015, 3:33 https://doi.org/10.12688/f1000research.3-33.v2

First published: 31 Jan 2014, 3:33 https://doi.org/10.12688/f1000research.3-33.v1 


\section{REVISED Amendments from Version 1}

Sections of text, in the Discussion in particular, have been modified according to the suggestions of the reviewers.

See referee reports

\section{Introduction}

Cornelia de Lange Syndrome (CdLS) is a genetic disorder that can lead to several alterations. It affects both physical and neuropsychiatric development. The several abnormalities include facial dysmorphia (arched eyebrows, synophrys, depressed nasal bridge, long philtrum, down-turned angles of the mouth), upper-extremity malformations, hirsutism, cardiac defects, and gastrointestinal alterations ${ }^{1}$. The prevalence of this syndrome is approximately one per $15,000^{2}$. Many markers have to be considered. Nuchal translucency (NT) measurement during the first trimester screening between 11 and 14 weeks gestation has now been clearly identified as a marker for aneuploidies and in particular for trisomy 21. Even in the absence of aneuploidy, increased foetal nuchal translucency has been shown to be a marker for foetal heart malformations and several other foetal defects linked to genetic syndromes when the measure exceeds the $95^{\text {th }}$ percentile $(3-5 \mathrm{~mm})^{3}$. When conventional karyotyping is normal, enlarged NT is a strong marker for adverse pregnancy outcome, associated with miscarriage or intrauterine death). Unspecified genetic syndromes involving developmental delay may only emerge after birth and become evident after the first years of life. Several abnormalities have been reported in foetuses with enlarged NT: the majority are cardiac defects, diaphragmatic hernia, exomphalos, body stalk anomaly, skeletal defects, certain genetic syndromes (such as congenital adrenal hyperplasia), foetal akinesia, deformation sequence, Noonan syndrome, Smith-lemli-Opitz syndrome and spinal muscular atrophy ${ }^{4}$. The saddle nose, characterized by a markedly depressed bridge has been described in AIDS embryopathy, Christ-Siemans-Touraine syndrome, various deletion syndromes, foetal trimethadione syndrome, Laron-type dwarfism, leprechaunism, multiple epiphyseal dysplasia, otospondylomegaepiphyseal dysplasia (OSMED) syndrome, relapsing polychondritis, thanatophoric dwarfism, Wegener's granulomatosis, and various conditions that are further characterized by gargoyle-like faces. Micrognathia is a malformation of the foetal face characterized by a small mandible. Micrognathia may be idiopathic but is more commonly associated with many different syndromes. Retrognathia (recession of the chin) is assessed through the measurement of the inferior facial angle, as defined on a mid-sagittal view. With routine ultrasound, the receded chin may be observed on a profile of the face. Yet, this diagnosis is often missed during a routine ultrasound examination. The mandible is known to grow significantly during the third trimester. If mandibular alteration is suspected, particular attention should be paid to the growth of the chin throughout the remainder of the pregnancy. Conditions associated with micrognathia include chromosomal abnormalities, neuromuscular abnormalities, single-gene disorders, and other syndromes. The prognosis of foetal micrognathia is poor, even in chromosomally normal foetuses. Frequent malformations associated with micrognathia are: Pierre Robin sequence (micrognathia, cleft palate, or both $)^{5}$; Cerebrocostomandibular syndrome (diagnosed on the basis of micrognathia, a posterior cleft palate defect, and characteristic rib gap abnormalities); Cornelia de Lange syndrome, (underdeveloped chin with tetralogy of Fallot, intrauterine growth restriction, and an abnormal right hand) ${ }^{6}$; hypochondrogenesis type II and Caffey disease.

\section{Case report}

We report a case of a healthy 31-year-old, gravida 2, para 1 at 30 weeks of gestation that was admitted to S. Bambino University Hospital in Catania for ultrasound examination. Ultrasounds revealed nuchal oedema, saddle nose, micrognathia with receding jaw, low set ears, facies senilis at 3D ultrasounds, arthrogryposis of the hands, absence of Aranzio's ductus venous, dilation of gallbladder and bowel, single one umbilical artery, increased volume of amniotic fluid. Intrauterine growth retardation was associated as well. (Figure 1) Micrognathia was evident on midsagittal and 3D scan. The biparietal diameter was $68 \mathrm{~mm}$, femur length $47 \mathrm{~mm}$, suggesting foetal growth restriction. Pulsed Doppler sonography showed normal middle cerebral artery and umbilical artery pulsatility indices. The obstetric history revealed increased nuchal translucency thickness (NT) at 11 weeks ( $4 \mathrm{~mm},>95$ centile). No genetic alterations were found at the amniocentesis carried out during $16^{\text {th }}$ week of pregnancy (normal karyotype of 46, XX). Morphological ultrasound at 22 weeks of pregnancy was not able to detect the syndrome. A further ultrasound examination at 29 weeks (Figure 2) of pregnancy pointed out a foetal dysmorphism and the pregnant woman asked for our consultation.

Soon after, interruption of pregnancy occurred. The autopsy showed a foetus with a weight between the $5^{\text {th }}$ and the $10^{\text {th }}$ percentile and a dysmorphic syndrome with malformation features amenable to CdLS (Figure 3). The foetus had a typical dysmorphic face, hirsutism, rhizomelic limb, bilateral camptodactyly, single transverse palmar crease, proximal and very short inches with hypoplasia of $1^{\text {st }}$ metacarpal and single phalanx, II-III membranous syndactyly of feet, right diaphragmatic hernia, bilateral cryptorchidism, microcephaly, numerous nodules of heterotopic cerebellar vermis, single umbilical artery and hypotrophic placenta devoid of inflammatory lesions.

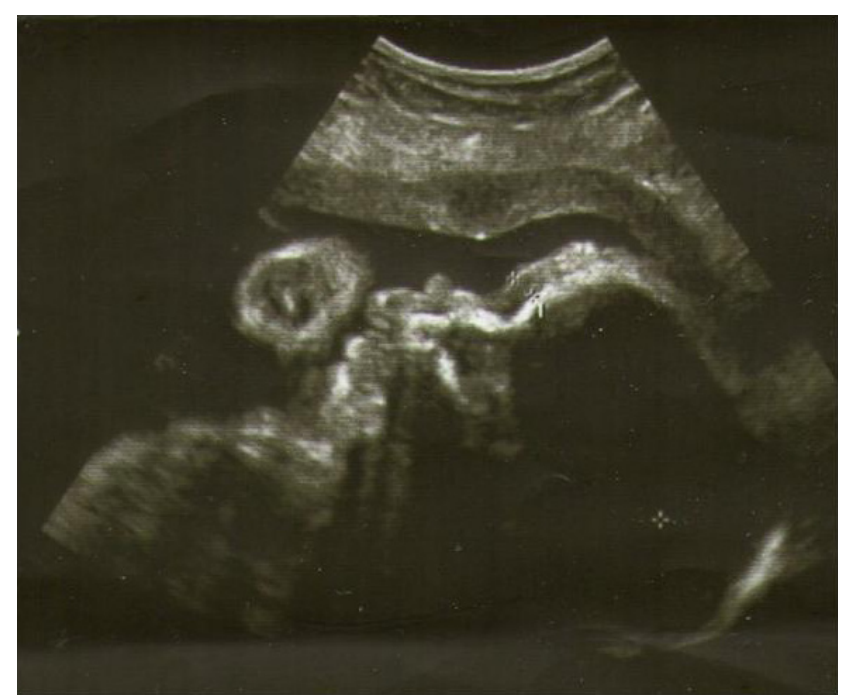

Figure $1.30^{\text {th }}$ week face profile with ultrasound. 


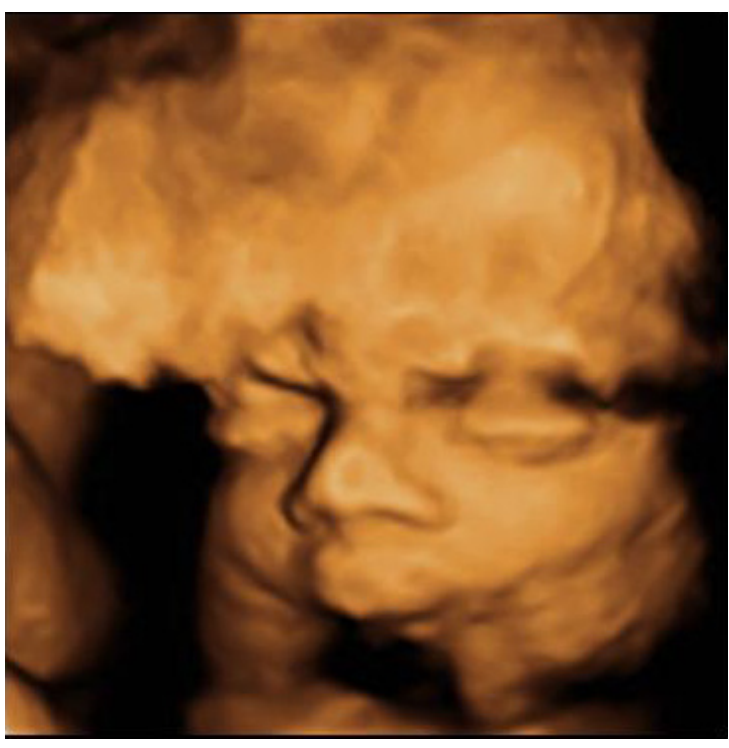

Figure 2. $\mathbf{2 9}^{\text {th }}$ week face aspect with 3D ultrasound.

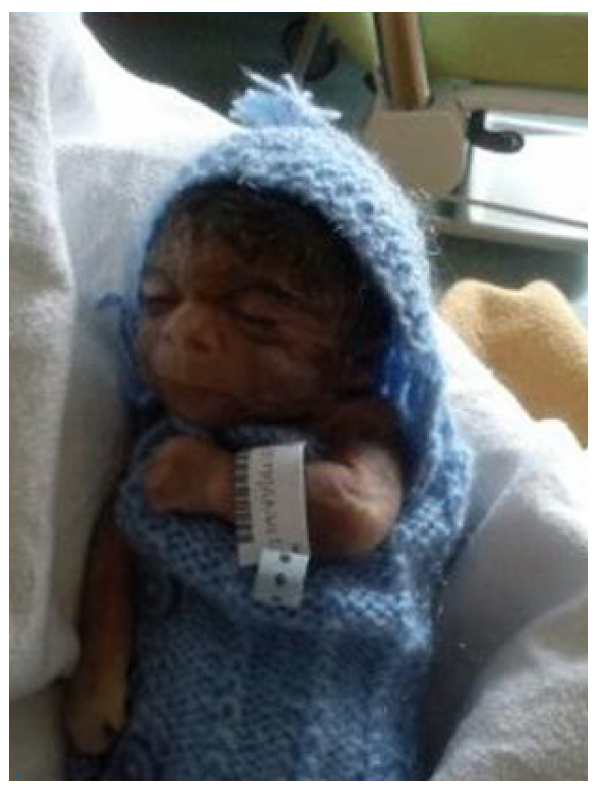

Figure 3. Aspect of the new born (facies senilis).

\section{Discussion and conclusion}

CdLS is a multisystem malformation syndrome recognized primarily on the basis of the morphological characteristics (malformations of the cranial, cardiac, gastrointestinal, and skeletal systems) ${ }^{7}$. However, there is wide clinical variability of disorders, with milder phenotypes that may be difficult to ascertain on the basis of physical features. In certain cases the diagnosis may be missed when ultrasound examination is not performed accurately. Criteria to detect CdLS are not standardized. The main alterations are as follows?

- Facial abnormalities (synophrys, long eyelashes, microcephaly, anteverted nostrils)
- Cardiac defects (defects of ventricles or atria, aortic or pulmonary stenoses, tetralogy of Fallot, atrioventricular canal, single ventricle, aorto-pulmonary window, truncus arteriosus communis)

- Abnormalities of upper limbs (ectrodactylia and monodactylism)

- Gastrointestinal alterations (diaphragmatic hernia)

- Musculoskeletal malformation

- Intrauterine growth retardation

Ultrasound detection of eyelashes is considered a clue for prenatal diagnosis of CdLS, but it can be missed in clinical practice ${ }^{10}$. CdLS is considered a cohesinopathy. Mutations in cohesin, or its regulators, cause a spectrum of human developmental syndromes. Cohesinopathy disorders include both CdLS and Roberts Syndrome. The discovery of novel roles for chromatid cohesion proteins in regulating gene expression led to the idea that cohesinopathies are caused by dysregulation of multiple genes downstream of mutations in cohesin proteins. Consistent with this idea, there is an altered expression of developmental genes and an incomplete overlap among dysregulated genes in different components of the cohesin apparatus ${ }^{11}$. CdLS is considered a dominantly inherited congenital malformation disorder, caused by mutations in the cohesin-loading protein NIPBL for nearly $60 \%$ of individuals. In humans, the multisubunit complex cohesin is made up of $S M C 1, S M C 3, R A D 21$ and a $S T A G$ protein. These form a ring structure that is proposed to encircle sister chromatids to mediate sister chromatid cohesin; it also has a key role in genetic regulation. In CdLS cell lines an altered transcription with either NIPBL or HDAC8 mutations has been found ${ }^{12}$. The proteins produced from mutated genes interfere in the foetal development. Within cells, these proteins help regulate the structure and organization of chromosomes and are involved in the repair of damaged DNA. They also regulate the activity of certain genes in the developing limbs, face, and other parts of the body. Researchers are looking for additional changes in the NIPBL, SMCIA and SMC3 genes, as well as mutations in other genes, that may be responsible for this condition. The majority of cases result from new gene mutations and occur in people with no family history. CdLS can be prenatally diagnosed in a family with a known mutation in a CdLS gene. The characteristic ultrasonographic profile may allow for prenatal diagnosis of CdLS in subsequent pregnancies for couples with a prior child with CdLS in whom a mutation has not been identified or when there are unexplained signs of foetal abnormality during pregnancy, such as oligo- or polyhydramnios, a low maternal serum PAPP-A level and/or increased NT, foetal growth retardation, or structural anomalies consistent with $\mathrm{CdLS}^{13}$. Data from mutational testing on known CdLS genes (NIPBL, SMC1A, SMC3, $R A D 21$, and $H D A C 8$ ) are important in the diagnosis of the typical syndrome. Indeed, the article published by Clark et al. $(2012)^{13}$ recommends molecular analysis of CdLS genes to prenatal diagnosis of CdLS. In our case data from mutational testing on known CdLS genes (NIPBL, SMC1A, SMC3, RAD21, and HDAC8) was negative and so we consider this a case of atypical CdLS. Mutations in NIPBL are not present in all cases and they account for about $60 \%$ of CdLS; while mutations in SMC1A and SMC3 only for a small percentage ${ }^{14}$. In some cases the diagnosis is made prenatally 
in other cases the syndrome is diagnosed after childbirth. Currently, there are no definitive prenatal screening measures that lead to the diagnosis of $\mathrm{CdLS}^{13}$. Fewer than $1 \%$ of individuals diagnosed with CdLS have an affected parent ${ }^{14}$. Recommendations for the evaluation of parents of a proband with an apparent de novo mutation include clinical examination for features of CdLS as well as the plotting of the growth parameters and the molecular genetic testing for NIPBL mutation compared to the one identified in the proband. In our atypical Cornelia de Lange syndrome case molecular tests, conducted on the blood samples of the parents in a sequential manner of for NIPBL, SMC1A, SMC3, RAD21 and HDAC8, were negative. The diagnosis is indicated when there is a major longitudinal deficiency defect of the upper limb, severe prenatal and postnatal growth retardation, and severe mental retardation. Features used to make the correct diagnosis include penciled and arched eyebrows, a high set/short anteverted nose, a long flat philtrum, a thin upper lip, downturned corners of the mouth, and micrognathia. Characteristics that are misleading include full or flat brows, a prominent nasal bridge or bulbous tip, and/or a normal or prominent chin. The genetic tests with positive results confirm the presence of the syndrome while the negative results do not exclude it. Indeed, mutations in NIPBL, SMCIA and SMC3 are not present in all cases of CdLS as in our case. Less than $1 \%$ of individuals diagnosed with CdLS have an affected parent ${ }^{14}$. As genetic and biochemical tests are unreliable at present, antenatal detection depends upon identification of some aspects of the phenotype in the foetus using ultrasound imaging ${ }^{15,16}$. When the syndrome is not recognized during pregnancy, the newborn may survive with a low quality of life and, thus, medical team could become involved in surgical procedures ${ }^{17}$. Each malformation causes an impact in the psychological sphere of both the individual and the family ${ }^{18}$. Last but not the least, the failure of an early diagnosis may lead to medical-legal issues ${ }^{19-21}$.

\section{Consent}

Written informed consent for publication of clinical details and clinical images was obtained from the patient and her husband.

\section{Author contributions}

LV: conception and design. RG: performed the ecography and drafted the article. All authors revised the manuscript for intellectual content and approved the final manuscript for publication.

\section{Competing interests}

No competing interests were disclosed.

\section{Grant information}

The author(s) declared that no grants were involved in supporting this work.

\section{Acknowledgements}

Special thanks to Professor Salvatore Sciarretta and Andreea Olteanu for their precious help in revising the English version of this work.
1. Noor N, Kazmi Z, Mehnaz A: Cornelia de Lange syndrome. J Coll Physicians Surg Pak. 2012; 22(6): 412-3.

PubMed Abstract

2. Murray JE, Walayat M, Gillett $P$, et al:: An atypical facial appearance and growth pattern in a child with Cornelia de Lange Syndrome: an intragenic deletion predicting loss of the N-terminal region of NIPBL. Clin Dysmorphol. 2012; 21(1): 22-3.

PubMed Abstract | Publisher Full Text

3. Senat MV, Frydman R: Increased nuchal translucency with normal karyotype. Gynecol Obstet Fertil. 2007; 35(6): 507-15. PubMed Abstract | Publisher Full Text

4. Mula R, Goncé A, Bennásar M, et al:: Increased nuchal translucency and normal karyotype: perinatal and pediatric outcomes at 2 years of age. Ultrasound Obstet Gynecol. 2012; 39(1): 34-41.

PubMed Abstract | Publisher Full Text

5. Hsieh YY, Chang CC, Tsai HD, et al:: The prenatal diagnosis of Pierre-Robin sequence. Prenat Diagn. 1999; 19(6): 567-569. PubMed Abstract | Publisher Full Text

6. Berney TP, Ireland M, Burn J: Behavioural phenotype of Cornelia de Lange syndrome. Arch Dis Child. 1999; 81(4): 333-336. PubMed Abstract | Publisher Full Text | Free Full Text

7. de Lange C: Sur un type nouveau d degenerescence (typus Amestelodamensis). Archives de Médecine des Enfants. 1933; 36: 713-719.

8. Bhuiyan ZA, Klein M, Hammond P, et al:: Genotype-phenotype correlations of 39 patients with Cornelia de Lange syndrome: the Dutch experience. $J$ Med Genet. 2006; 43(7): 568-575.

PubMed Abstract | Publisher Full Text | Free Full Text

9. Akahori $\mathrm{Y}$, Masuyama $\mathrm{H}$, Masumoto $\mathrm{Y}$, et al.: Three-dimensional ultrasound findings in cornelia de lange syndrome: a case report. Obstet Gynecol. 2012; 2012: 568351

PubMed Abstract | Publisher Full Text | Free Full Text

10. Spaggiari E, Vuillard E, Khung-Savatovsky $S$, et al:: Ultrasound detection of eyelashes: a clue for prenatal diagnosis of Cornelia de Lange syndrome. Ultrasound Obstet Gynecol. 2013; 41(3): 341-2. PubMed Abstract | Publisher Full Text

11. Horsfield JA, Print CG, Mönnich M: Diverse developmental disorders from the one ring: distinct molecular pathways underlie the cohesinopathies. Front Genet. 2012; 3: 171

PubMed Abstract | Publisher Full Text | Free Full Text

12. Deardorff MA, Bando M, Nakato R, et al.: HDAC8 mutations in Cornelia de Lange syndrome affect the cohesin acetylation cycle. Nature. 2012; 489(7415): 313-7.

PubMed Abstract | Publisher Full Text | Free Full Text

13. Clark DM, Sherer I, Deardorff MA, et al.: Identification of a prenatal profile of Cornelia de Lange syndrome (CdLS): a review of $53 \mathrm{CdLS}$ pregnancies. Am J Med Genet A. 2012; 158A(8): 1848-56.

PubMed Abstract | Publisher Full Text | Free Full Text

14. Deardorff MA, Clark DM, Krantz ID, et al.: Cornelia de Lange Syndrome. 2011. PubMed Abstract

15. Leanza V, Sciarretta S: Fundamental obstetric and gynecologic elements. (Test Book) Editor S.p.e. Catania, (Italy). 2011; ISBN 978-88-96808-05-4.

16. Leanza V: OBSTETRICS Editor MINERVA MEDICA S.P.A. Torino (Italy). 2009; (ISBN 13 978-88-7711-631-4). Reference Source

17. Zanghì G, Di Stefano G, Leanza V, et al.: Incisional hernia in Day Surgery: our personal experience. G Chir. 2012; 33(6-7): 218-20. PubMed Abstract

18. Leanza V, Passanisi A, Leanza G: A specific application of two psychological measures on female urinary incontinence: perceived negative affective selfefficacy scale and stress psychological measure. Urogynaecologia International efficacy scale and stress psych
Journal. 2011; 25: N², 41-48.

19. Leanza G, Palumbo M, Marilli I, et al: Double atresic uterus associated with agenesis of cervix and third upper of vagina. Giornale Italiano di Ostetricia e Ginecologia. 2013; 35(1): 262-264. Reference Source

20. Genovese F, Risoleti EVI, Rubino C, et al.: Epidemiological study on toxoplasmosis in pregnancy: Effectiveness of the screening. Giornale Italiano di Ostetricia e Ginecologia. 2011; 33(5): 259-263. Reference Source

21. Altomare M, La Vignera S, Asero $\mathrm{P}$, et al.: High prevalence of thyroid dysfunction in pregnant women. J Endocrinol Invest. 2013; 36(6): 407-11.

PubMed Abstract | Publisher Full Text 


\section{Open Peer Review}

\section{Current Peer Review Status: ? $\checkmark$ ?}

\section{Version 2}

Reviewer Report 10 December 2015

https://doi.org/10.5256/f1000research.4647.r4026

(C) 2015 Çetin 0. This is an open access peer review report distributed under the terms of the Creative Commons Attribution License, which permits unrestricted use, distribution, and reproduction in any medium, provided the original work is properly cited.

\section{Orkun Çetin}

Obstetrics and Gynecology, Istanbul Suleymaniye Birth and Gynecology Training and Research Hospital, Istanbul, Turkey

I appreciate your work and thank you for your effort. However I have some considerations to be clarified.

1. The manuscript needs a light sub-edit for the English.

2. The authors made the final diagnosis only with the clinical findings. However, there were not any photos that confirmed CdLS. If possible, the autopsy photos should be added to the manuscript.

The manuscript could be accepted after minor revisions.

Competing Interests: No competing interests were disclosed.

I confirm that I have read this submission and believe that I have an appropriate level of expertise to confirm that it is of an acceptable scientific standard, however I have significant reservations, as outlined above.

Reviewer Report 28 May 2015

https://doi.org/10.5256/f1000research.4647.r8779

(C) 2015 Jackson L. This is an open access peer review report distributed under the terms of the Creative Commons Attribution License, which permits unrestricted use, distribution, and reproduction in any medium, provided the original work is properly cited.

\section{Laird Jackson}

Department of Obstetrics and Gynecology, Drexel University, Philadelphia, PA, USA 
The authors have responded appropriately to the earlier comments except in one instance. It may be due to language differences but the term "unreliable" should not be used to describe the genetic tests referred to in the paper. The tests are "reliable" if performed properly; in that they do or do not demonstrate a copy-number change (if by microarray) or a point mutation (if by some means of genome sequencing. What the authors intend to say is that a negative test (i.e. one that does not demonstrate a molecular change), is not equivalent to ruling out the clinical diagnosis. So they might simply say that the molecular tests are only "conclusive" in about $60-70 \%$ of the clinically recognized cases.

Competing Interests: No competing interests were disclosed.

\section{I confirm that I have read this submission and believe that I have an appropriate level of expertise to confirm that it is of an acceptable scientific standard.}

\section{Version 1}

Reviewer Report 14 April 2014

https://doi.org/10.5256/f1000research.1212.r4483

(C) 2014 Jackson L. This is an open access peer review report distributed under the terms of the Creative Commons Attribution License, which permits unrestricted use, distribution, and reproduction in any medium, provided the original work is properly cited.

\section{Laird Jackson \\ Department of Obstetrics and Gynecology, Drexel University, Philadelphia, PA, USA}

I agree with the report and comments of Dr Jinglian Liu, who has also reviewed this article. The case report is interesting in its detail of the prenatal ultrasound examination and observations, but completely fails its responsibility to connect those observations to appropriate use of contemporary molecular diagnostic opportunities. As such, this article fails the medical community by not accepting the opportunity to connect their useful prenatal morphological observations to detectable objective molecular findings.

Competing Interests: No competing interests were disclosed.

I confirm that I have read this submission and believe that I have an appropriate level of expertise to confirm that it is of an acceptable scientific standard, however I have significant reservations, as outlined above.

Reviewer Report 14 February 2014

https://doi.org/10.5256/f1000research.1212.r3450 
(c) 2014 Liu J. This is an open access peer review report distributed under the terms of the Creative Commons Attribution License, which permits unrestricted use, distribution, and reproduction in any medium, provided the original work is properly cited.

\section{Jinglan Liu}

Department of Pediatrics, Drexel University, Philadelphia, PA, USA

This manuscript describes a fetus with clinical features suggestive of Cornelia de Lange Syndrome (CdLS).

My comments are as follows:

1. Data from mutational testing on known CdLS genes (NIPBL, SMC1A, SMC3, RAD21, and HDAC8 ) would be important for this case. The article published by Clark et al. (2012) which was also cited by the authors, recommends molecular analysis of CdLS genes to prenatal diagnosis of CdLS.

2. The authors should compare prenatal findings in the current case with what described in the article by Clark et al. (2012). Without molecular testing data, I would like to see a table demonstrating the current case presenting prenatal clinical features consistent with what has been documented in the literature by studying a larger cohort of probands.

3. In the discussion, in the beginning of first paragraph, the authors claim that CdLS is diagnosed primarily by morphological characteristic and cited a paper published in 1933. At present, the diagnosis criteria of CdLS cannot be the same as what was 90 years ago, particularly with the identification of specific gene mutations in CdLS probands. Please rephrase this part, and cite updated references.

4. In the end of the discussion, what does it mean "genetic tests are not reliable"? As a matter of fact, molecular testing has become a widely accepted concept and a popular diagnostic approach for individuals with congenital anormalies.

Minor things:

1. OMIM numbers of CdLS and disease genes should be given.

2. Please double check the spelling and eliminate typographic errors, also, some terms are not accurately used. Below is listed some examples of those errors:

Abstract - "kariotype" -> "karyotype"

Introduction - "psychical" - > I'd like to use "neuropsychiatric"

$2^{\text {nd }}$ paragraph in case report - "dimorphism" -> "dysmorphism"

$2^{\text {nd }}$ paragraph in discussion - "cohesion" -> "cohesin"

$2^{\text {nd }}$ paragraph in discussion - please italicize the gene names "NIPBL" and "HDAC8"

$2^{\text {nd }}$ paragraph in discussion - "familiarity" ? What does it mean? Why not change to " no family history" 
Competing Interests: No competing interests were disclosed.

I confirm that I have read this submission and believe that I have an appropriate level of expertise to confirm that it is of an acceptable scientific standard, however I have significant reservations, as outlined above.

Author Response 01 Sep 2014

vito leanza, Catania University, Catania, Italy

1. "Data from mutational testing on known CdLS genes (NIPBL, SMC1A, SMC3, RAD21, and HDAC8) would be important for this case. The article published by Clark et al. (2012) which was also cited by the authors, recommends molecular analysis of CdLS genes to prenatal diagnosis of CdLS."

In our case report, data from mutational testing on known CdLS genes (NIPBL, SMC1A, $S M C 3, R A D 21$, and $H D A C 8$ ) are negative, indeed it was called atypical Cornelia de Lange Syndrome (CdLS).

Mutations in NIPBL are not present in all cases and they account for about $60 \%$ of CdLS; mutations in SMC1A and SMC3 account for a small percentage (Deardorff et al., 2011).

2. "The authors should compare prenatal findings in the current case with what described in the article by Clark et al. (2012). Without molecular testing data, I would like to see a table demonstrating the current case presenting prenatal clinical features consistent with what has been documented in the literature by studying a larger cohort of probands."

Cornelia de Lange Syndrome (CdLS) is a multisystem developmental disorder characterized by growth retardation, cognitive impairment, external and internal structural malformations, and characteristic facial features. Currently, there are no definitive prenatal screening measures that lead to the diagnosis of CdLS. (Clark et al. 2012).

In our case (atypical CdLS) increased nuchal translucency in the first trimester, normal karyotype, saddle nose, micrognathia with receding jaw, low set ears, facies senilis, arthrogryposis of the hands, absence of the Aranzio ductus venous, dilatation of gallbladder and bowel, a unique umbilical artery, increased volume of amniotic fluid, and intrauterine growth retardation were found.

Fewer than $1 \%$ of individuals diagnosed with Cornelia de Lange syndrome have an affected parent.

Recommendations for the evaluation of parents of a proband with an apparent de novo mutation include clinical examination for features of CdLS, complete with plotting of growth parameters and molecular genetic testing if the NIPBL mutation has been identified in the proband. In our atypical Cornelia de Lange syndrome 
molecular tests of parents were negative.

3. "In the discussion, in the beginning of first paragraph, the authors claim that CdLS is diagnosed primarily by morphological characteristic and cited a paper published in 1933. At present, the diagnosis criteria of CdLS cannot be the same as what was 90 years ago, particularly with the identification of specific gene mutations in CdLS probands. Please rephrase this part, and cite updated references."

Diagnosis is based on clinical findings. High-resolution ultrasound examination to follow growth and to evaluate the limbs, heart, diaphragm, palate, and other organs or structures affected in CdLS is fundamental. Reported prenatal ultrasound findings include: increased nuchal translucency in the first trimester [Sekimoto et al., 2000; Huang \& Porto, 2002]; Growth failure, which typically presents in the second trimester; and the typical in utero facial profile of a fetus with CdLS consisting of micrognathia, a prominent upper lip, and a depressed nasal bridge with somewhat anteverted nares [Ranzini et al., 1997; Boog et al., 1999; Urban \& Hartung, 2001].

4. "In the end of the discussion, what does it mean "genetic tests are not reliable"? As a matter of fact, molecular testing has become a widely accepted concept and a popular diagnostic approach for individuals with congenital anormalies."

Genetic tests are not reliable when negative. On the contrary when positive they are important for syndrome.

Indeed, mutations in NIPBL are not present in all cases and they account for about $60 \%$ of CdLS; mutations in SMC1A and SMC3 account for a small percentage ( Deardorff et al., 2011).

Minor things:

These minor things are easy to correct. I thank the first referee for his clarifications.

Competing Interests: No competing interests were disclosed. 
The benefits of publishing with F1000Research:

- Your article is published within days, with no editorial bias

- You can publish traditional articles, null/negative results, case reports, data notes and more

- The peer review process is transparent and collaborative

- Your article is indexed in PubMed after passing peer review

- Dedicated customer support at every stage

For pre-submission enquiries, contact research@f1000.com 